\title{
Some Observations on the Use of Social and Political Indicators in International Trade Risk Assessment
}

\author{
by Aran Schloss*
}

\section{Introduction}

The assessment of international trade risks is an attempt to reduce uncertainty in a field characterized by complex interdependence between social, political and economic forces. A relatively advanced stage in the development of economic indicators enables students and practitioners of international trade to employ these analytical tools for both diagnostic and prognostic purposes. However, experience and a vast volume of studies suggest that risks involved in international trade are rarely caused by economic forces alone. Accordingly, assessment of risks in this field requires analysis of modes of interaction between social, political and economic forces and their impact on economic activity. Second, this interdisciplinary approach also dictates the establishment of social and political indicators that would complement the economic indicators already employed in risk assessment practices.

The following discussion addresses several aspects of this interdisciplinary approach. The discussion opens with two examples which illustrate the need to include analysis of social and political factors in risk assessment practices. These examples include a brief review of events in Iran during 1977-1979 and a presentation of non-economic aspects of the budgetary process in the less developed countries (LDCs). On the basis of these case studies, the discussion proceeds to elaborate on categories of non-economic indicators. Three major categories are presented - social, political and administrative. In each category examples are given of indicators included therein. The third and concluding part of our discussion deals with the issue of measurability in the behavioral science and its implications to risk assessment practices.

The discussion refers primarily to risk assessment concerning trade with the LDCs. The LDCs are characterized by high degree of economic, social and political uncertainty. In fact, these countries reflect most clearly the multidimensionality of international trade risks.

* Lecturer in the Department of Political Science, Tel Aviv University and a Research Fellow at the Harry S. Truman Research Institute for the Advancement of Peace at the Hebrew University of Jerusalem. 


\section{Why social and political indicators?}

\section{Example 1: IRAN}

Review of statistical data on the Iranian economy during 1974-1977 did not reveal any early warning signs of the eventual collapse of the Shah's regime. Moreover, upon considering the development programs pursued by the Shah during the Fifth Five Year Plan (1973-1978), the monies funnelled into different sectors of the economy and the regime's close control of the political system, Iran's economy could not be considered any less attractive or more risky in 1977 than in 1976 or in 1972 . Risk assessment reports published during 1976-77 merely suggested that the Iranian economy might experience a slower rate of growth and some cuts in budget expenditure in the industry sector and in military equipment purchases.

Subsequent events in Iran during 1978 and early 1979 led private companies and public organizations throughout the world to re-examine their risk assessment techniques. Ex post facto analysis of earlier risk reports reveals that in most, if not all cases, the social and political forces that eventually shaped the process of change in Iran were either ignored or misinterpreted. For instance, an 80 years old exiled religious leader proved astonishingly capable of using common communication technology (tape cassettes) to incite strikes and demonstrations throughout the country. The messages sent by Khomeini found a highly receptive audience at home. An 'impossible' coalition of the Shah's foes, comprised of the extreme left, liberals and ultra-religious groups, combined forces and succeeded in driving the presumably 'invincible' ruler out of the country. The 'strongest army in the region' together with other forces loyal to the Shah proved incapable of meeting the challenge of the opposition. What is more, it became apparent that economic growth and vigorous attempts to promote economic modenization do not necessarily secure stability or the political survival of the regime. Second, Khomeini's success suggested that exposure to the forces of modernization does not necessarily entail an irreversible process of change in society.

The need to consider social and political aspects of economic activity is certainly not limited to a single country. In fact, the growth of the public sector in both industrialized countries and LDCs implies that the dynamics of change in the national economy of every country could be better comprehended upon considering the impact of social and political forces on the process of managing the economy.

\section{Example 2: Budgeting}

In the LDCs, political uncertainty and limited consensus are major causes behind some 'peculiar' modes of budgetary behavior that undermine economic growth. More specifically, in these countries, approval by the legislature of the Governement Budget is not considered a final and abiding decision on resource allocations for the upcoming fiscal year. Rather, it is often perceived as an interim stage in an ongoing annual competition over means of action. Participants may be willing to adhere to appropriation decisions as long as their demands are reasonably satisfied. Other participants whose demands were not met are inclined to seek changes in these decisions and in this process tend to apply various forms of pressure (bribery, implicit agreements, threats to remove support from government, establishing new coalitions, inciting social unrest, etc.). Lack of accepted rules that all participants abide by, entails supplementary budgets which increase inflation and uncertainty. This lack of consensus also produces the so called 'repetitive budgeting' i.e. bargaining and negotiations over items of 
expenditure continue long after they were formally approved. In both cases, uncertainty increases for all participants and government units find themselves lacking assurances as to allocations each will acutally receive during the fiscal year.

To deal with this uncertainty, if only for the sake of organizational survival, government units adopt various measures and tactics. One common practice, which is also found in the industrialized countries, is to submit much inflated budget requests in the hope that after it is cut, the amount actually given will be of the size the unit aimed at all along. Another practice is the establishment of 'autonomous funds'. This is done in several different ways, one of which is to attain the status of an autonomous agency which is budgeted by earmarked taxes or charges for services or foreign aid. Another way is to estimate expenditure high and revenue low so as to create surplus and reduce financial dependence on the central government. This 'flexibility' is also achieved by yet another way that exploits the central government's limited control capabilities - a unit reports on expenditures without actually spending the money. Ironically, under these circumstances each party increases its 'certainty' by passing on uncertainties to someone else. The effect of these practices is reflected in the 'disappearing budget': the amount of money flowing in the system is a mystery to all participants. The disappearing budget thus becomes an obstacle to successful implementation of economic policies if only because it presents the policy makers with the task of finding where the economy actually stands and what are the driving forces behind it.

Seen from the perspective of the finance ministry, this financial environment appears to be as turbulent and volatile. Demands for goods and services far exceed available resources. At the same time the ability to reject demands without causing administrative or political or social unrest is acutely limited. What is more, the finance ministry operates on the basis of data that is grossly incomplete and frequently inaccurate. Hence, decisions are delayed until the last possible moment and when made they often prove only marginally related to the economy's immediate needs. The minister of finance, himself a political figure, is also expected to respond favorably to the needs of the political leadership and strong interest groups and to ensure his own political survival. The combined effect of these circumstances (scarcity of financial resources, insufficient data on the economy, lack of consensus over rules, political instability and widespread favoritism) is sustained uncertainty. It entails 'printing machine budgeting' and 'cash-flow budgeting' - both of which are conductive to high and rising inflation rates and the predominance of immediate political interests over economic considerations.

\section{Categories of social and political indicators}

The foregoing discussion on Iran and on the budgetary process presented examples of non-economic factors that influence the course of the economy and affect a country's risk rating. These factors impinge on the economy of both industriallized countries and LDCs but they appear to affect the latter in ways that undermine economic growth. Indeed, different grading methods employed by the Berne Union members rank the LDCs high on their respective risk scales, whereas the industrialized countries and in particular the western democracies are ranked closer to the other end of the scale. This ranking order is explained by the fact that the industrialized countries are politically stable, their economies are well developed and strong and their social structure is based on sound foundations, i.e., well-established consensus on values, norms and 'rules of the game'. Put differently, a country's position on the risk 
scale is determined by the degree of certainty (or, predictability) that characterizes its economy and its social and political system. Yet, the prevailing grading methods seem to determine the degree of certainty by using the measurable and relatively well-developed economic indicators, whereas the use of social and political indicators is at best limited.

The following discussion suggests several categories of social and political factors that constitute part of a basis for interdisciplinary risk assessment.

\subsection{Social indicators}

Social Heterogeneity: Society's ethnic composition; religious and cultural division.

What are society's groups - types of heterogeneity

$$
\text { - size of groups }
$$

Social stratification: distribution of social groups in sectors, regions, occupations. "Ethnic" professions, control of regions and sectors - control of social resources. Mobility opportunities.

National Social market vs. local markets: Scope and types of group interaction; exchange of social resources - availability of national social resources, forms and scope of exchange; predominant values. What are the status symbols? Productivity of social resource exchange.

Elite composition and social establishment: Major establishments - Army, Church, Political Bureaucratic, Rural; Elite - homogeneity/heterogeneity; Relations among social establishments; Establishments' control of economic resources.

Urbanization: rate of growth of urban centers - scope of rural migration, number of towns, emerging social groups.

Risk parameters: Prospects of social instability increase as conditions are characterized by:

- High rate of rural migration and limited employment opportunities in urban centers.

- Government's failure to provide services to urban poor including expanding employment opportunities (budget allocations and programs).

- Middle class intelligentsia (primarily students) combines forces with city poor (urban guerilla).

- Church is economically independent and pursues social policies that contradict government's policies.

- Society is heterogeneous, consensus over basic values is limited, different groups are more or less of comparable size.

Communication and Transport: mass-types, consumption by which groups/ regions, channels of communication and the mediators (who translates, who controls); transportation networks - geographical distribution and traffic density, social interaction, opportunities and ideas, marketing opportunities.

\subsection{Political indicators}

Political participation and power distribution : party organization and membership (ethnic, regional, national political parties' control of economic resources, regime's representation of 
groups and regions, regime's control of political system - means and practices, change in the political system - 'rules of game', frequency of change, modes of change; predominant forms of participation).

Opposition politics: established opposition, political dissent - scope forms of organization, modes of operation, ethnic/geographic distribution, control of social resources (social support).

Political legitimacy: consensus over basic values and rules of the government process, public support of established political institutions (Legislature, Judiciary, Elections).

The exogeneous political factor: country's strategic importance to major forces; foreign aid size, types, forms; vietnam Syndrome' - limited responsibility.

\section{Risk parameters}

- Ethnically based parties undermine establishment of effective central government; they tend to promote highly politicized bureaucracy; shifting coalitions, inconsistent policies.

- Military regimes are confronted with 'legitimacy problem'; emphasis on political control increase, use of coercive force promotes conflicts, prospects of counter coup increase.

- Prospects of political instability increase as opposition party gains support of social institutions that control some communication channels (Church).

\subsection{Administrative indicators:}

Politicized bureaucracy: political/power distribution in government's administrative machinery - who control which part of the bureaucracy (political parties, ethnic groups); the politics of recruiting personnel; "political" uses of administrative information (reporting constraint).

Planning, plans and implementation: the implementation gap' - programs sectors, regions; data basis for planning and the politics of a planning process; consumers of plans; administrative capacity - sectors, geographical regions - manpower, data, equipment, coordination.

Budgeting:Allocation vs actual expenditure - order of priority (proposed/actual), regions, sectors; spending capacity; absorptive capacity (change in sectors, areas); programs outside government budget (sectors/activities/groups, political uses).

\section{Risk parameters:}

- Budget document provides yet another means to identify distribution of power in society and the political compromises made at a given point of time: who gets what; comparison of allocation vs actual expenditure reveals who actually received what: analysis over time reveals real order of priority among sectors and regions as well as the relative power of participants.

- Ethnic, geographic, political affiliation of high echelon officials reveal group control of government administrative machinery and could suggest prospects of successful/ problematic interministerial cooperation and coordination. 


\section{On measurability}

The debate on the possibility of any significant measurement in the behavioral science remains to be resolved. However, it has already yielded some widely accepted observations:

I. The mystique of quantity : the re is an exaggerated regard for the significance of measurement, just because it is quantitative, without regard either to what has been measured or to what can subsequently be done with the measure.

Example: Level of health in society is measured by number of occupied beds in hospitals. Is it really the level of health that we are measuring or, possibly, the level of sickness? If the latter, how many sick people are not hospitalized? How do we define "health"?

II. The mystique of quality: Quantitative measurement does not belong to the study of human behavior because it either leaves out or distorts what is really important.

Example: The intelligence measured by IQ tests rarely, if ever, includes capacities such as creativity.

(Note: the tests do not measure everything we might like to think of as intellectual capacity, but it does not necessarily follow that the measure is a poor one. Rather, it is merely suggested that the measure should be interpreted somewhat less inclusively).

III. Rarely if ever does a single quantitative description or a single qualitative description tell us everything about an observed phenomenon.

Examples: What is a 50 kilo table? What is a nice table? What is the significance of a $3 \%$ rate of growth in agricultural productivity in India? What makes an industrialized country a postindustrialized country?

IV. Between unaided individual judgement and strict quantitative measurement there are many intermediate measurement devices which enable us to carry on systematic study. They include: systematic ratings, ranking scale, multidimensional classifications, typologies and simple quantitative devices.

Each of these observations is applicable to the categories of social and political indicators discussed earlier. First, the predominance of quantitative measurement proved somewhat counter-productive in the assessment of international trade risks. Second, the social and political indicators are primarily qualitative and many are measurable by intermediate measurement devices. These indicators complement the economic indicators and enable a more comprehensive assessment of a multidimensional phenomenon such as international trade risks. Moreover, the integrative-interdisciplinary approach is essential to assessment of risks in this field. Yet, if our risk assessment capacity is to be improved, the development of social and political indicators has to be further pursued.

\section{Appendix: The integrative approach applied - Saudi Arabia and Kuwait}

Saudi Arabia and Kuwait, two neighboring Moslem count ries share over 30 percent of the world's known oil reserves. Kuwait, is a small country with an area of $17,818 \mathrm{sq}$. km. and a population of approximately 1.3 million, whereas Saudi Arabia extends over a vast territory of $2,500,000 \mathrm{sq} . \mathrm{km}$. and has a population estimated at 8.7 million. A monarchy and an emirate, 
respectively, Saudi Arabia and Kuwait pursued limited development programs throughout the 1960s and early 1970s without distinguishing themselves. However, following the first sharp increase in the price of oil, January 1974, both countries embarked on an unprecedented large economic expansion program that far exceeded their plans. Since 1975, Saudi Arabia has been operating with an annual budget 22 to 34 times larger than its budget for fiscal year (FY) 1970. Similarly, Kuwait's annual budget from FY 1975 to FY 1980 was 6 to 13 times larger than its budget for FY 1970. In both countries, increased expenditures applied to all sectors of the economy. By FY 1979, Saudi Arabia had allocated to no ${ }_{n}$-oil sectors sums of betwee $n 6$ and 28 times more than they had been allocated in FY 1970. In comparison, Kuwait has acted somewhat more moderately, increasing allocations to its non-oil sectors $b_{y} 200$ percent $t_{0} 500$ pepcent. The non-oil sectors emphasized by Kuwait included electricity and water, housing, transport and communication and health. Saudi Arabia, lacking the somewhat more developed infrastructure found in Kuwait, was obliged to invest considerably more in the infrastructure itself and in the social services and distribution sectors. This included transport, communications, construction, wholesale and retail trade and government services.

Seeking to modernize their economies but faced with the severely limited capacity of indigenous manpower to perform a wide variety of tasks required for development, Saudi Arabia and Kuwait deployed their wealth to recruit the expertise of foreign firms and brought in an unprecedentedly large expatriate labor force. Conservative estimates suggest that since 1975, Saudi Arabia has contracted out developent projects in every sector of the economy at a total cost exceeding $\$ 80,000$ million. Similarly, the number of expatriate workers employed in Saudi Arabia has risen to an estimated 2 million people (i.e., approximately 25 percent of the population). Kuwait has contracted out projects in excess of $\$ 6,000$ million and the number of foreign workers employed in the Kuwaiti economy has been estimated at 70-75 percent of the total workforce and 53 percent of the total population! In both countries, the expatriate labor force is comprised of white-collar professionals, blue-collar skilled workers and unskilled laborers alike.

Having established an economy characterized by a large-scale multisectoral development operation and a supply of exogeneous manpower and technology, these two less developed wealthy countries (LDWCs) witnessed the expansion of their physical infrastructures, social services, economic and human resources. During its second Five-Year plan, 1975-1980, Saudi Arabia achieved a 133 percent increase in installed electric power, construction of more than 350,000 residential dwelling units and an increase of 76 percent in the network of paved roads; electric output increased fivefold, the consumption of refined petroleum products quadrupled and imports rose by more than 400 percent. During this period, student enrollment expanded by 35 percent, the number of vocational training centers rose from 9 to 26 and the number of hospital beds increased by 68 percent; the average annual growth rate of nominal GDP reached 23 percent; and in nominal terms, the share of the non-oil sectors rose from 20 percent (fiscal year 1974-75) to 34 percent (FY 1979-80). Measured in 1969-70 prices, the annual average growth rate of real non-oil GDP surpassed the Plan's target and reached 15 percent. This growth rate, substained despite the slowdown in government spending (19761978), reflects improved utilization of a significantly larger domestic capital stock and of manpower resources that have been built up since 1974. Considerable expansion has also characterized the Kuwaiti economy. Estimates indicate that the real growth rate in the non-oil sector accelerated from an annual average rate of about 9 percent in 1972-75 to 25 percent in 1976; in the subsequent two years 1977-1978 this growth rate decelerated but remained relatively high. 
A strong and rising trend toward greater domestic utilization of savings (i.e., the level of domestic capital formation) became evident starting in 1975. From 1976 to 1980 the Government's National Housing Authority (NHA) is said to have built more than 20,000 dwellings. Installed electric capacity more than doubled and imports rose by 300 percent. Student enrollment is said to have doubled and the number of Kuwaiti women entering the labor market has increased as well. Growth has also been evident in petrochemical and non-oil manufacturing industries, a reflection of the efforts made to broaden the base of the economy.

\section{Modernization characterized by growth and stability}

The unprecedented growth so recently achieved by Saudi Arabia and Kuwait has been mainly due to the unique advantages enjoyed by both countries since 1974 , rather than by virtue of exceptional capabilities acquired in the course of the national development effort. Specifically, control over oil production and the impact of the oil embargo on the world economy afforded their political clout and a steadily growing volume of revenue. Endowed with these resources, both countries enjoyed considerable flexibility to pursue development in a style unparalleled among less developed countries. Surplus revenue, for example, has provided them with the ability to pursue development uninhibited by the need to establish a strict preference order for investment. In practice, it has enabled them to finance numerous development operations simultaneously and support them over a relatively long period of time. What is more, the combination of wealth and political clout has enabled them to launch a development efforts on a scale far exceeding their indigenous capacities. This translates into the ability to meet emerging needs in the economy and to shift emphasis in sectoral development strategies without necessarily reducing the volume of investment in any sector or undermining the interest of economic groups. Moreover, unlike other less developed countries, Saudi Arabia and Kuwait have been able to secure the cooperation of industrialized countries and choose from among goods and services offered to them in large quantities by foreign corporations and governments. Implied in this situation are both the security of a "back-up system" for required goods and services and a measure of flexibility in dealing with partners for development.

These advantages have had far-reaching implications on the process of development in both countries, enabling them to resolve operational difficulties in development projects and subsequently improve the prospects for success in these programs. In practice, surplus revenue has accorded them considerable capacity to withstand and absorb the impact of inefficiency. More importantly, it has enabled them to maintain support to programs through the length of time often needed for these activities to evolve into well-organized operations. Indeed, compared with the experience of other LDCs, the number of programs these two LDWCs had to discontinue for lack of funds or because of unsatisfactory progress remains significantly small. Further, when faced with unsatisfactory performance on part of local personnel, Saudi Arabia and Kuwait have enjoyed the option and resources to recruit foreign experts and laborers that would either assist local manpower or perform the development tasks independently.

Endowed with surplus revenue, Saudi Arabia and Kuwait have also been able to distribute the benefits of development broadly to different groups in society. In fact, within a relatively short period of time, they have established a fairly extensive network of social and welfare services. Local citizens have been offered education and health services free of charge as well 
as easy credit terms for housing and personal loans. The government has established producer and consumer subsidies (food, travel, utilities, gasoline). Trainees and apprentices have been provided with various forms of secured income and a wide variety of employment opportunities. Similarly, a growing number of students have been sent abroad at the government's expense to complete their higher education and foreign experts have been recruited to provide vocational education and training to local personnel. These two LDWCs then have been able to provide citizens with incentives presumably conducive to both the maintenance of the public's satisfaction and the development of indigenous capabilities. Moreover, by adopting this mode they have attracted local participation in new forms of economic activity that constitute part of the attempt to achieve economic modernization.

Development under conditions of wealth has yet another advantage of considerable significance: the population's preoccupation with economic opportunity. In this regard, Saudi Arabia and Kuwait have, thus far, avoided the impediments inherent in the so-called "development syndrome" (e.g., social and political dissatisfaction caused by incapacity to satisfy rising economic demands) by following a "modus operandi" which other LDCs could not afford on a nationwide scale. Recognizing their capacity to satisfy a wide range of growing economic demands and emphasizing their determination to preserve the status quo in the political system, the House of Al-Saud (Saudi Arabia) and the House of Al-Sabah have encouraged growing economic demand. In practice, wealth became the means for offering citizens attractive opportunities for employment and upward economic mobility. Further, to maintain the public's preoccupation with economic activity, the regime has increased the number and scope of programs in the public sector as well as the support given to entrepreneurs in the private sector on a scale that either met or surpassed demands. Wealth, then, became the means for reducing the risk of economic dissatisfaction which might lead to unwarranted pressures on the political system. ${ }^{1}$ Moreover, by implementing a policy of "abundant economic opportunities", the regimes have, in all probability, enhanced the population's awareness of the risks instability would bring to bear on their own economic interests and wellbeing. Wealth, then, became the means to promote a politically tranquil process of rapid economic and social change.

\section{The destabilizing forces of development under conditions of Wealth}

Although wealth enabled Saudi Arabia and Kuwait to achieve an unusually peaceful revolution, development under conditions of wealth established several potentially destabilizing forces never before confronted by other LDCs. In particular, this involves the exposure of society to intense, "all-out" development activity and the recruitment of an exceptionally large expatriate labor force. What is more, the hitherto fruitful development efforts may prove themselves to be a major source of instability neither wealth nor abundant economic opportunities will suffice to resolve.

\footnotetext{
${ }^{1}$ It should, however, be noted that this modus operandi has not necessarily been a product of preplanned and carefully prepared strategy. Instead, it might have been a process that evolved out of the "pressure of wealth" and limited administrative capacities, the combination of which led to uncontrollable multi-sectoral distribution of development programs thereby creating public preoccupation with the exploitation of economic opportunities. Either way, the outcomes has thus far served the regimes' interests by preserving the status quo in the political system while enhancing economic modernization.
} 
In comparison to other LDCs, Saudi Arabia and Kuwait exposed individuals, groups, and society as a whole to rapid and radical changes in standard of living, employment opportunities, the need and opportunity for new forms of social interaction, housing and urbanization. Similarly, they exposed the society to advanced technology and production techniques, new forms of modern organization, new roles (consumers and producers alike), new educational opportunities and groups of expatriate workers who represent a wide spectrum of social and cultural values. The intensity of this multi-faceted exposure has no precedent. Further, wealth may have created a tendency to indulge in the exploitation of unprecedented opportunities without addressing the impact of change on individuals and on society as a whole. Viewed from this perspective, the peaceful revolution may be seen as a stage during which destabilizing social and economic forces are introduced into society without causing immediate disruption. Thus, the society may maintain a facade of stability but performance may hinge on increasingly eroding premises. Subsequently, the society may be victimized by a delayed shock - i.e., widespread anomie and confusion breaking out once the public is confronted with the results of the initial stages of this mode of modernization.

Given the pressure of modernization on different aspects of social life and the exceptional "support systems" established by surplus revenue, these LDWCs may yet encounter the results of incongruity between different sets of values and norms. This may be manifested in a growing apathy among different groups or growing dissent and opposition, particularly among the newly recruited bureaucrats, small merchants, and the less educated clientele of the newly established public services who are confronted with unfamiliar and possibily threatening roles, rules, and responsibilities. The society, then, may have outgrown the era of exploiting unprecedented opportunities and may be approaching a stage where it has to attend to the establishment of a sound basis for sustained growth. In this regard, Kuwait appears to be in a somewhat more advantageous position. Considering the size of the country and the infrastructure established prior to the large-scale development activity, the Kuwait society has been more widely exposed to modernization over a longer period of time. What is more, although an Islamic country, Kuwait is not burdened with Saudi Arabia's responsibilities as protector of Islam's holy places (Mecca and Medina). And, Kuwait has exhibited a greater flexibility in translating into practice the idea of "development in the framework of Islamic values and social practices". For instance, Kuwait has permitted and often even encouraged the participation of women in the labor force. Similarly, this LDWC has been experimenting with a form of representative assembly, establishing "modern" channels of communication and socialization alongside the "traditional" networks. Finally, the size of the population and the bureaucratic machinery in Kuwait may present the regime with a somewhat less difficult task in detecting and addressing early signs of delayed shock.

Another crucial challenge facing these two LDWCs involves the prospective social and political implications of establishing an economy based largely on expatriate labor. The issue pertains to both the substantial representation of foreign workers in the labor force and in the population and the incongruity between these workers' role in the economy and the discriminating policies they are subjected to. Second, it involves the cost to the society of the emerging "Rentier society" phenomenon.

Official figures published by the Saudi Arabia authorities estimate that the number of non-Saudi workers increased from 494,000 in 1975 to 1,060,000 in 1980. However, observers suggest that the actual number is considerably higher, perhaps as high as 2 million. In Kuwait, the latest official census (1975) estimated the number of foreigners at 53 percent of the 
population. However, unofficial estimates suggest that in 1980 the percentage of foreigners rose to 57 percent. In both countries the largest group of expatriate laborers was of Arab nationals (1.0 to 1.5 million in Saudi Arabia and 400,000 to 500,000 in Kuwait) followed in size by non-Arab Asian workers (700,000 to 800,000 in Saudi Arabia and 50,000 inKuwait) and Western workers $(100,000$ and 15,000). These workers fill positions that Saudis and Kuwaitis are either unqualified for or unwilling to accept. Given the sizeable investment in the economy and the privileges enjoyed by Saudis and Kuwaitis to choose from among the more lucrative employment opportunities, the need for and the dependence on the services of foreign workers increased. Subsequently, their role in the economy became of crucial importance for sustained economic growth. However, while permitting and often encouraging the influx of expatriate laborers, both countries have imposed severe restrictions on the rights of these workers. In Kuwait, they are not permitted to own property, homes, or business and non-Arab workers have been deprived of the free education available to Arabs. Saudi Arabia has acted similarly. In both countries, these restrictions have applied to all foreign workers and their dependents, irrespective of the length of time they have resided in the country. In practice, these discriminating policies have neither reduced the number of new workers arriving annually nor have they increased the turnover among foreign workers. Consequently, Saudi Arabia and Kuwait have evolved into societies where an increasingly growing part of the population is subjected to discrimination while its role in the economy is gaining increased importance.

This constellation has not presented Saudi Arabia and Kuwait with serious difficulties, since the foreign workers have thus far remained unassuming in their demands for rights. Furthermore, with almost no exception, these workers failed to organize. Indeed, it is often argued that the majority of the foreign workers are solely concerned with their economic wellbeing and will not jeopardize their source of income by antagonizing the local authorities. However, never before have these workers been represented in such large numbers in the economy. Accordingly, size may prove a catalyst to change in at titude among the foreign workers. Similarly, neither the house of Al Saud nor the house of Al Sabah can assume that due to the diverse cultural and ethnic background of these groups of workers, they will fail to organize. Rather, it can be assumed that the longer these workers reside in the country, the more inclined they will become to demand changes in the discriminatory policies, particularly if their economic role gains increased importance. It can also be assumed that several groups among the foreign workers may become involved in political affairs that concern their country of origin (Palestinians, Somalis, and Eritreans) and subsequently become better organized and more capable of representing the interests of their community in the host country. Saudi Arabia and Kuwait may therefore find themselves in an increasingly vulnerable position. Refusal on part of the regime to accept demands from a well-organized group may yield growing tensions and possibly cause disruptions in the economy and a rising sense of instability. Acceptance of the demands of one group may, however, pose the threat of mounting pressure from other groups and subsequently a rising sense of vulnerability. The benefits of these LDWCs' ability to compensate for limited indigenous capacities may thus prove extremely costly, both socially and economically. Further, unlike other LDCs, the recruitment of expatriate labor force presents Saudi Arabia and Kuwait with the need to address both the impact of modernization on the indigenous population and the potential threats from economically important but discriminated-against groups of alien residents.

Viewed from another perspective, the recruitment of expatriate labor presents these LDWCs with an emerging "Rentier society" phenomenon inherently incongruous with the 
desire to become self-reliant. This is manifested in the evolution of a "Rentier class" whereby local citizens act as "silent partners" in businesses established by foreign citizens. The locals draw an income from these enterprises simply because they have "loaned" their citizenship to firms foreigners could not otherwise establish. What is more, the availability of foreign workers combined with the National Insurance Programs and social services for citizens enable Saudis and Kuwaitis to avoid employment in professions they deem unacceptable. It also enables a growing number of citizens to obtain training in white-collar professions and assume supervisory positions with higher social status as well as higher income. Consequently, a two-tier system is evolving whereby most of the low income, low-status positions are held by foreigners. This appears to be acompanied by an emerging unfavorable attitude on part of local citizens toward numerous professions that are essential for the proper functioning of every society (unskilled construction workers, street sweeping and sanitation, low-level maintenance personnel, to mention just a few). Accordingly, the regimes' attempts to promote self-reliance may become politically costlier as local citizens and foreign workers share a common interest.

Finally, the availability of foreign labor coupled with the hitherto successful transformation of citizens into producers and consumers of public goods and services presents yet another source of potential instability. The issue pertains to the impact of exposing citizens to the process of managing public affairs and the prospective implications of increased citizens' participation in the process of government. In keeping with the experience of other LDCs, development in Saudi Arabia and Kuwait has entailed a mushrooming bureaucracy. However, unlike other LDCs, these LDWCs were also able to promote considerable growth in the private sector. What is more, the recruitment of foreign labor has led to the assignment of a growing number of Saudi and Kuwaiti citizens to supervisory positions. Given the other services and employment opportunities offered to citizens, these measures have led to both a considerable exposure of the public to the process of government and an uncommonly rapid increase in the scope of citizens' participation in the process of managing public affairs. This, however, has not led the house of Al Sabah, much less the house of Al Saud to decentralize decision-making authority. Saudi Arabia and Kuwait have therefore succeeded in establishing a much enlarged network of interactions between citizens and government agencies without encountering difficulties in maintaining highly centralized government. In this regard, wealth may have enabled both countries to introduce their citizens to the process of government in a rather uncommon way: while participation is encouraged and inefficiency is easily absorbed, citizens are given new roles without being "burdened" by decision-making authority. Nevertheless, given this success and the growing share of citizens in the management of public affairs, both LDWCs may be approaching a new stage in the relations between citizens and the regime. On the one hand, the mushrooming bureaucracy presents the regime with increased difficulties to monitor the administrative machinery. Similarly, bureaucrats' frustration may be growing due to the gap between their responsibilities and the limited decision-making authority they are given. On the other hand, both regimes may fall victim to these LDWCs' capacity to absorb inefficiency, failing to address bureaucratic frustration before it becomes a major problem. A diminishing capacity to monitor the bureaucracy, coupled with the discretion bureaucrats actually exercise while implementing policies (i.e., the power of implementation) may entail change in the power of the ruling political elite vis-a-vis the administrators. This in turn may result in growing demands for change in the distribution of power, presenting the regime with increased prospects for instability. In this regard, Saudi Arabia and Kuwait may have exhausted their capacity to transform emerging political demands into satisfiable 
economic demands The success in turning a growing number of citizens into better educated participants who are involved in the production and consumption of public goods and services may imply an increasingly rising cost for maintaining both economic modernization and growth and the political survival of autocratic regimes.

\section{Sustained peaceful revolution or prelude to chaos?}

The preceding analysis suggests that the process of modernization in LDWCs differs significantly from the experience of other LDCs. The peaceful revolution witnessed in Saudi Arabia and Kuwait over the last decade indicates the uncommon capacity of LDWCs to compensate for limited administrative capacity and shortage of skilled personnel. This however does not necessarily imply a capacity to establish a sound basis for sustained economic growth. Similarly, while LDWCs are capable of transforming emerging political and social demands into satisfiable economic demands, they are not necessarily more effective than other LDCs in maintaining political stability beyond the early phases of the modernization. Nevertheless, LDWCs differ from LDCs in their capacity to delay and cushion the impact of modernization upon society by creating and enhancing the public's preoccupation with economic opportunities. In Huntington's terms then, modernizing LDWCs reduce social frustration by increasing both social mobilization and the rate of economic development. What is more, they offer abundant opportunities for social and economic mobility. Further, they deploy surplus revenue to attract citizens' participation in the economy and promote this road for advancement of the socially mobilized individuals. In this regard, both LDWCs discussed here have, thus far, succeeded in resolving the "king's dilemma" in a unique mode - citizens' exposure to and participation in the government process is increasing without presenting an immediate threat to the highly centralized regime. Accordingly, by maintaining the centralized authority needed for policy innovation, both LDWCs may have been spared the political chaos witnessed in other LDCs. What is more, these LDWCs may have unintentionally promoted the establishment of a reasonably broad reservoir of participating citizens capable of providing for a less rather than more disruptive transition to a new political system. Hence, a relatively low level of social frustration, during the early phases of modernization, coupled with abundant mobility opportunities and rapid economic growth may prove conducive to the broadening of political participation. Further, this mode of political participation may prove compatible with the political survival of a centralized regime. However, given the new interdependance that emerges between participating citizens and the ruling elite, this mode of political participation may evolve into a source of instability. The lack of adaptable political institutions, as may prove to be the case in Saudi Arabia, could set the emerging reservoir of participating citizens and the ruling elite on a collision course. Adaptability and flexibility which appear to be emerging in the Kuwaiti system may prove conducive to a peaceful transition, to a system where authority derives from popular consent through elections, parties and legislatures. This may assume the form of a ruling monarchy transformed peacefully into a reigning monarchy, or it may evolve in a form that combines monarchial rule and representative government.

Although capable of achieving rapid economic growth, LDWCs may however fall victim to their own spending capacity and fail to establish a sound basis for sustained growth. The dilemma they face pertains to a conflict between the opportunity to achieve rapid growth through the recruitment of foreign manpower and the more time-consuming task of establishing a broad range of indigenous capacities conducive to sustained growth. While the two 
are not inherently incompatible, LDWCs appear to be incapable of resisting the pressure of their own wealth. They tend to launch development activity which far exceeds their indigenous capacities while lacking the ability and possibly the inclinations to establish functional compatibility between development operations and the promotion of a braod range of local capabilities. Consequently, the achievement of a rapid economic growth is divorced from indigenous capacities to maintain sustained growth. What is more, the attempt to change the course of the economy and in particular the distribution of indigenous manpower in the economy are becoming politically costlier. This, in turn, places the LDWCs at a stage where the increased social mobility becomes a source of pressure to maintain development spending irrespective of its contribution to growth in indigenous capacities, resembling the situation in many LDCs. 